\title{
PENINGKATAN KESELAMATAN \\ DI RUAS JALAN PANTURA KM 46-47 KECAMATAN PATROL KABUPATEN INDRAMAYU
}

\author{
Arivia Shehera Kurniastuti \\ Politeknik Transportasi Darat \\ Indonesia-STTD \\ Jln. Raya Setu No. 89 \\ Kota Bekasi, Jawa Barat \\ (021) 8254640 \\ arivia.shehera@gmail.com
}

\author{
Novita Sari \\ Politeknik Transportasi Darat \\ Indonesia-STTD \\ Jln. Raya Setu No. 89 \\ Kota Bekasi, Jawa Barat \\ (021) 8254640 \\ novita.s@ptdisttd.ac.id
}

\author{
Sulistyo Sutanto \\ Politeknik Transportasi Darat \\ Indonesia-STTD \\ Jln. Raya Setu No. 89 \\ Kota Bekasi, Jawa Barat \\ (021) 8254640 \\ sulistyo.sutanto1703@gmail.com
}

\begin{abstract}
The number of traffic accidents that occur in Indramayu Regency continues to increase and causes many casualties and material losses. From the available data, it is known that there is one road section which is an accident-prone area, namely the North Coast Java Road section, KM 46-47, which is located in Patrol District, Indramayu Regency. The flow and speed of traffic on this road is quite high, because of its function as a primary arterial road. This study aims to improve safety on the North Coast Java Road section, KM 46-47. The method used is in the form of observation and field data collection. Furthermore, the data obtained is processed, analyzed, and followed by formulating appropriate recommendations. This study shows that the main cause of accidents is the human factor, especially those related to high traffic speeds. To improve the existing conditions, it is proposed to provide road equipment, especially traffic signs, which are adjusted to the stopping sight distance required by motorized vehicles using the road. In addition, it is necessary to apply speed management as part of efforts to improve traffic safety.
\end{abstract}

Keywords: traffic accident; stopping sight distance; road equipment, traffic speed; traffic signs.

\begin{abstract}
Abstrak
Angka kecelakaan lalu lintas yang terjadi di Kabupaten Indramayu terus meningkat dan menyebabkan banyak korban jiwa dan kerugian material. Dari data yang ada diketahui bahwa terdapat satu ruas jalan yang termasuk daerah rawan kecelakaan, yaitu ruas Jalan Pantai Utara Jawa, KM 46-47, yang terletak di Kecamatan Patrol, Kabupaten Indramayu. Arus dan kecepatan lalu lintas di ruas jalan tersebut cukup tinggi, karena fungsinya sebagai jalan arteri primer. Studi ini bertujuan untuk meningkatkan keselamatan di ruas Jalan Pantai Utara Jawa KM 46-47. Metode yang digunakan berupa observasi dan pengumpulan data lapangan. Selanjutnya data yang diperoleh diolah, dianalisis, kemudian dirumuskan rekomendasi yang tepat. Studi ini menunjukkan bahwa faktor penyebab kecelakaan yang utama adalah faktor manusia, khususnya yang berhubungan dengan kecepatan lalu lintas yang tinggi. Untuk memperbaiki kondisi yang ada, diusulkan pemberian perlengkapan jalan, khususnya rambu lalu lintas, yang disesuaikan dengan jarak pandang henti yang diperlukan oleh kendaraan bermotor yang melintasi jalan tersebut. Selain itu perlu diterapkan manajemen kecepatan sebagai bagian upaya meningkatkan keselamatan lalu lintas.
\end{abstract}

Kata-kata kunci: kecelakaan lalu lintas; jarak pandang henti; perlengkapan jalan, kecepatan lalu lintas; rambu lalu lintas.

\section{PENDAHULUAN}

Dari tahun 2016 sampai dengan tahun 2018, jumlah kecelakaan lalu lintas yang terjadi di Kabupaten Indramayu turun sebesar 44\%. Namun, jumlah korban kecelakaan meninggal dunia yang terjadi meningkat 4 kali lipat, yaitu dari 91 orang menjadi 376 orang. 
Data statistik kecelakaan lalu lintas yang diperoleh dari Kepolisian Resort Kabupaten Indramayu menunjukkan bahwa dari 4 faktor penyebab kecelakaan lalu lintas, faktor penyebab yang dominan adalah faktor manusia, yaitu sebesar $76 \%$, khususnya karena kecepatan yang tinggi, yaitu sebesar 52,14\%. Hal ini dipengaruhi oleh kondisi jalan, yang berupa jalan lurus menerus namun tidak dilengkapi dengan perlengkapan jalan, berupa rambu, serta penerangan jalan yang tidak berfungsi. Kondisi ini berpotensi membahayakan pengguna jalan yang melintasi jalan tersebut. Untuk itu, perlu dilakukan usaha untuk meningkatkan keselamatan lalu lintas sehingga dihasilkan suatu jalan yang berkeselamatan.

Tujuan studi ini adalah memberikan rekomendasi penanganan jalan, dalam upaya meningkatkan keselamatan lalu lintas di ruas Jalan Pantura KM 46-47, Kecamatan Patrol, Kabupaten Indramayu. Lokasi studi dapat dilihat pada Gambar 1.
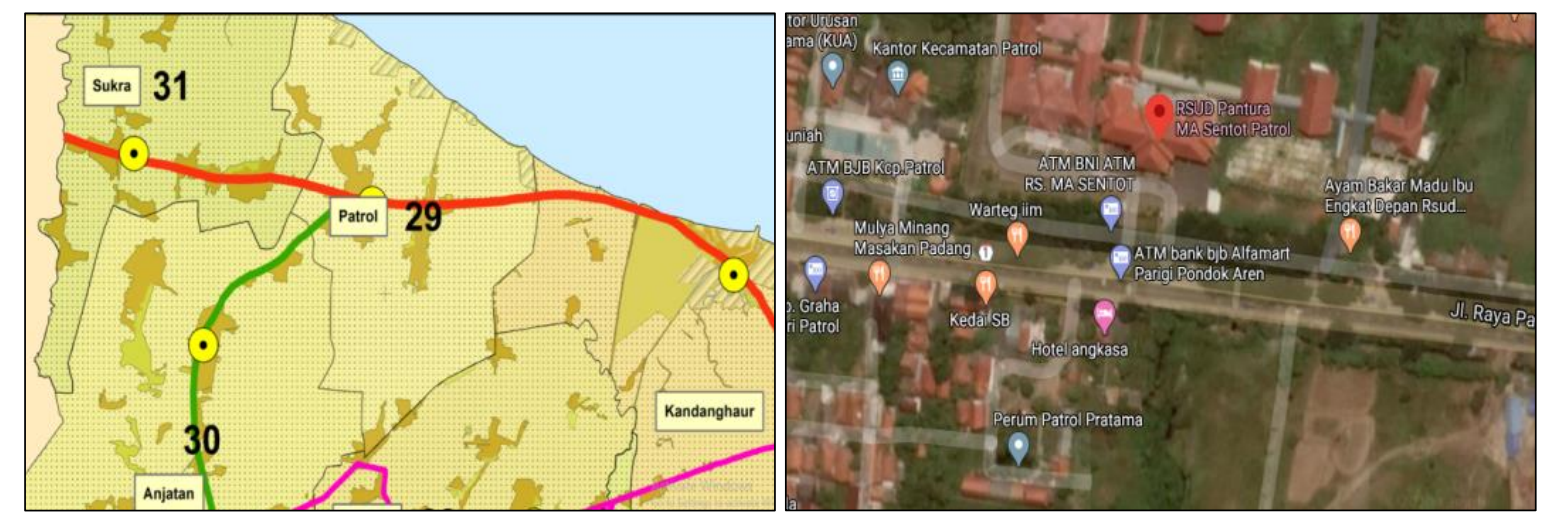

Gambar 1 Lokasi Penelitian

Menurut UU Nomor 22 tahun 2009, Pasal 1, kecelakaan lalu lintas adalah suatu peristiwa di jalan yang tidak diduga dan tidak disengaja, yang melibatkan kendaraan dengan atau tanpa pengguna jalan lain, yang mengakibatkan korban manusia dan/atau kerugian harta benda. Kecelakaan lalu lintas digolongkan menjadi 3 jenis, yaitu kecelakaan lalu lintas ringan, kecelakaan lalu lintas sedang, dan kecelakaan lalu lintas berat. Kecelakaan lalu lintas ringan merupakan kecelakaan lalu lintas yang mengakibatkan kerusakan kendaraan dan/atau barang, kecelakaan lalu lintas sedang merupakan kecelakaan yang mengakibatkan luka ringan dan kerusakan kendaraan dan/atau barang, dan kecelakaan lalu lintas berat merupakan kecelakaan yang mengakibatkan korban meninggal dunia atau luka berat.

Faktor penyebab kecelakaan lalu lintas dapat dibagi menjadi 4 faktor, yaitu faktor manusia, faktor kendaraan, faktor jalan, dan faktor lingkungan. Sedangkan kecelakaan lalu lintas dapat terjadi dengan berbagai tipe tabrakan (Aswardi et al, 2017). Kejadian kecelakaan lalu lintas dibagi menjadi beberapa tipe berdasarkan kronologi kejadiannya, yaitu tabrak depan-depan, tabrak depan-belakang, tabrak depan-samping, tabrak samping-samping, dan lepas kendali. Kecelakaan lalu lintas dapat dihindari apabila ruas jalan dilengkapi dengan perlengkapan jalan, yang, antara lain, berupa rambu lalu lintas, marka jalan, alat pemberi isyarat lalu lintas, alat penerangan jalan, alat pengendali dan pengaman pengguna jalan, serta alat pengawasan dan pengamanan jalan, yang berada di jalan dan di luar badan jalan. 
Keamanan dan kenyamanan pengemudi kendaraan, untuk dapat melihat dengan jelas dan menyadari situasinya pada saat mengemudi, sangat bergantung pada jarak yang dapat dilihat dari tempat kedudukannya. Panjang jalan di depan kendaraan yang masih dapat dilihat dengan jelas diukur dari titik kedudukan pengemudi, dan disebut jarak pandangan. (Sukirman, 1999). Jarak pandang ini berguna untuk: (1) menghindarkan terjadinya tabrakan yang dapat membahayakan kendaraan dan manusia akibat adanya benda yang berukuran cukup besar, kendaraan yang sedang berhenti, pejalan kaki, atau hewan-hewan pada lajur jalannya, (2) memberi kemungkinan untuk mendahului kendaraan lain yang bergerak dengan kecepatan lebih rendah dengan mempergunakan lajur di sebelahnya, (3) menambah efisiensi jalan tersebut, sehingga volume pelayanan dapat dicapai semaksimal mungkin, dan (4) sebagai pedoman bagi pengatur lalu intas dalam menempatkan rambu-rambu lalu lintas yang diperlukan pada setiap segmen jalan.

Jarak pandang henti adalah jarak yang ditempuh oleh pengemudi untuk dapat menghentikan kendaraannya. Jarak pandang henti minimum merupakan jarak yang ditempuh pengemudi untuk menghentikan kendaraan yang bergerak setelah melihat adanya rintangan pada lajur jalannya. Jarak pandang henti terdiri atas 2 elemen jarak, yaitu jarak tanggap (Jht) dan jarak pengereman (Jhr).

Jarak tanggap adalah jarak yang diperlukan oleh suatu kendaraan sejak pengemudi melihat rintangan yang menyebabkan ia harus berhenti sampai saat pengemudi menginjak rem. Waktu yang dibutuhkan pengemudi dari saat dia menyadari adanya rintangan sampai dia mengambil keputusan disebut waktu PIEV, singkatan dari Perception, Intellection, Emotion, and Vollition. Jadi, waktu PIEV adalah waktu yang dibutuhkan untuk proses deteksi. Pengenalan, dan pengambilan keputusan. Besarnya waktu ini dipengaruhi oleh kondisi jalan, mental pengemudi, kebiasaan, keadaan cuaca, penerangan, dan kondisi fisik pengemudi. AASHTO (1990) menggunakan waktu PIEV sebesar 1,5 detik. Setelah pengemudi mengambil keputusan untuk menginjak rem, pengemudi membutuhkan waktu sampai dia menginjak pedal rem. Rata-rata pengemudi membutuhkan waktu (0,5-1) detik. Untuk perencanaan digunakan waktu sebesar 1 detik, sehingga total waktu yang dibutuhkan dari saat dia melihat rintangan sampai menginjak pedal rem, yang disebut sebagai waktu reaksi, adalah 2,5 detik. Jarak yang ditempuh selama waktu tersebut adalah:

$$
d_{1}=0,278 v \cdot t
$$

dengan:

$\mathrm{d}_{1}=$ Jarak dari saat melihat rintangan sampai menginjak pedal rem (m)

$\mathrm{v}=\operatorname{Kecepatan}(\mathrm{km} / \mathrm{jam})$

$\mathrm{t}=$ Waktu reaksi (2,5 detik).

Jarak pengereman adalah jarak yang ditempuh oleh kendaraan dari saat pengemudi menginjak pedal rem sampai kendaraan itu berhenti. Jarak pengereman ini dipengaruhi oleh kondisi ban, sistem pengereman itu sendiri, kondisi muka jalan, dan kondisi perkerasan jalan. Jarak pengereman dapat dihitung menggunakan rumus: 


$$
d_{2}=\frac{v^{2}}{254 f m}
$$

dengan:

$\mathrm{v} \quad=$ kecepatan kendaraan $(\mathrm{km} / \mathrm{jam})$

$\mathrm{fm}=$ koefisien gesekan antara ban dan muka jalan dalam arah memanjang jalan.

Dengan demikian persamaan jarak pandang henti adalah (Sukirman, 1999):

$$
J h=0,278 v \cdot t+\frac{v^{2}}{254 f m}
$$

dengan:

Fm = Koefisien gesekan antara ban dan muka jalan dalam arah memanjang

$\mathrm{D}$ = Jarak pandang henti minimum (m)

$\mathrm{v} \quad=$ Kecepatan kendaraan $(\mathrm{km} / \mathrm{jam})$

$\mathrm{t} \quad=$ Waktu reaksi (2,5 detik).

\section{METODOLOGI PENELITIAN}

Metode yang digunakan dalam penelitian ini berupa observasi. Kemudian data yang diperoleh diolah, dianalisis, dan selanjutnya diputuskan rekomendasi yang tepat untuk mengurangi tingkat kecelakaan dan keparahan kecelakaan.

Penentuan lokasi penelitian ini didasarkan pada peringkatan daerah rawan kecelakaan Kabupaten Indramayu. Ruas Jalan Pantura KM 46-47, Kecamatan Patrol, Kabupaten Indramayu, termasuk dalam 3 peringkatan daerah rawan kecelakaan di kabupaten tersebut.

Subyek penelitian meliputi semua kejadian kecelakaan lalu lintas yang terjadi di ruas Jalan Pantura KM 46-47, Kecamatan Patrol, Kabupaten Indramayu, yang tercatat dalam Unit Laka Lantas Kepolisian Resort Kabupaten Indramayu dalam kurun waktu tahun 2016 hingga tahun 2018. Jenis data meliputi data primer dan data sekunder. Pengumpulan data dilakukan dengan survei inventarisasi jalan, survei kecepatan sesaat, dan jumlah kecelakaan lalu lintas yang diperoleh dari Kepolisian Resort Kabupaten Indramayu. Analisis yang dilakukan pada studi ini meliputi analisis kecepatan, analisis geometrik jalan, dan analisis perlengkapan jalan, berupa rambu dan penerangan jalan.

\section{HASIL DAN PEMBAHASAN}

\section{Analisis Kecepatan}

Untuk mengetahui kecepatan rata-rata suatu ruas jalan, diperlukan survei spot speed Berdasarkan hasil survei yang telah dilakukan di lapangan, diperoleh hasil kecepatan kenda- 
raan yang melalui ruas Jalan Pantura KM 46-47 Kecamatan Patrol, Kabupaten Indramayu, sebagaimana ditampilkan pada Tabel 1.

Tabel 1 Kecepatan di Ruas Jalan Pantura KM 46-47 Kecamatan Patrol, Kabupaten Indramayu

\begin{tabular}{ccccccccc}
\hline & \multicolumn{1}{c}{ Jenis } & \multicolumn{1}{c}{ Masuk } \\
\cline { 2 - 9 } Kendaraan & $\begin{array}{c}\text { Maksimum } \\
(\mathrm{km} / \mathrm{jam})\end{array}$ & $\begin{array}{c}\text { Minimum } \\
(\mathrm{km} / \mathrm{jam})\end{array}$ & $\begin{array}{c}\text { Rata-Rata } \\
(\mathrm{km} / \mathrm{jam})\end{array}$ & $\begin{array}{c}\text { Persentil 85 } \\
(\mathrm{km} / \mathrm{jam})\end{array}$ & $\begin{array}{c}\text { Maksimum } \\
(\mathrm{km} / \mathrm{jam})\end{array}$ & $\begin{array}{c}\text { Minimum } \\
(\mathrm{km} / \mathrm{jam})\end{array}$ & $\begin{array}{c}\text { Rata-Rata } \\
(\mathrm{km} / \mathrm{jam})\end{array}$ & $\begin{array}{c}\text { Persentil 85 } \\
(\mathrm{km} / \mathrm{jam})\end{array}$ \\
\hline MC & 72,00 & 50,70 & 57,61 & 63,16 & 72,00 & 51,43 & 57,75 & 62,78 \\
LV & 90,00 & 50,00 & 63,12 & 78,26 & 83,72 & 49,32 & 62,16 & 78,26 \\
HV & 62,07 & 50,00 & 55,29 & 60,00 & 60,00 & 48,65 & 52,89 & 56,25 \\
\hline
\end{tabular}

Diketahui bahwa ruas Jalan Pantura KM 46-47, Kecamatan Patrol, Kabupaten Indramayu, memiliki kecepatan rata-rata yang cukup tinggi. Hal ini dikarenakan fungsi jalan adalah jalan arteri primer. Kondisi jalan, yang berupa jalan menerus, memicu pengemudi kendaraan bermotor untuk memacu kendaraannya dengan kecepatan tinggi, sehingga berpengaruh terhadap tingginya angka kecelakaan lalu lintas yang disebabkan oleh kecepatan tinggi tersebut.

\section{Analisis Geometrik}

Data penampang melintang menunjukkan bahwa jalan mempunyai lebar lajur 3,5 m, lebar median 1,5 m, lebar tepian median tidak ada, lebar bahu jalan $1 \mathrm{~m}$, dan lebar marka 0,1 meter. Kondisi eksisting jalan ini kurang sesuai dengan kriteria yang terdapat pada Standar Percencanaan Geometrik Jalan Perkotaan (Direktorat Jenderal Bina Marga, 1992), yang memberikan kriteria lebar lajur 3,5 m, lebar median $2 \mathrm{~m}$, lebar tepian median 0,5 m, dan lebar bahu jalan $2,5 \mathrm{~m}$.

\section{Jarak Pandang Henti}

Jarak pandang henti adalah jarak yang ditempuh pengemudi untuk dapat menghentikan kendaraannya. Guna memberikan keamanan pada pengemudi kendaraan, di setiap jalan harus tersedia jarak pandang henti minimum. Jarak pandang henti dihitung dari posisi mata pengemudi dan tidak hanya menyangkut kendaraan-kendaraan lain, tetapi juga dengan geometrik dan lokasi marka, rambu, dan lampu lalu lintas.

Tabel 2 Jarak Pandang Henti Arah Masuk Indramayu di Ruas Jalan Pantura KM 46-47

Kecamatan Patrol Kabupaten Indramayu

\begin{tabular}{ccccccc}
\hline \multirow{2}{*}{$\begin{array}{c}\text { Jenis } \\
\text { Kendaraan }\end{array}$} & $\begin{array}{c}\text { Kecapatan } \\
\text { Rencana } \\
(\mathrm{km} / \mathrm{jam})\end{array}$ & Fm & $\begin{array}{c}\text { Jarak } \\
\text { Pandang Henti } \\
\text { Eksisting } \\
(\mathrm{m})\end{array}$ & $\begin{array}{c}\text { Kecapatan } \\
\text { Persentil 85 } \\
(\mathrm{km} / \mathrm{jam})\end{array}$ & Fm & $\begin{array}{c}\text { Jarak } \\
\text { Pandang Henti } \\
(\mathrm{m})\end{array}$ \\
\hline MC & 60 & 0,33 & $75-85$ & 63,16 & 0,324 & 92,4 \\
LV & 60 & 0,33 & $75-85$ & 78,26 & 0,302 & 134,2 \\
HV & 60 & 0,33 & $75-85$ & 60,00 & 0,330 & 84,6 \\
\hline
\end{tabular}


Hasil analisis menunjukkan bahwa jarak pandang henti yang dibutuhkan oleh masingmasing jenis kendaraan melampaui jarak pandang henti eksisting (lihat Tabel 2 dan Tabel 3). Pada kajian ini, jarak pandang henti yang dibutuhkan oleh setiap jenis kendaraan dihitung dengan menggunakan kecepatan persentil ke-85 kendaraan-kendaraan tersebut.

Tabel 3 Jarak Pandang Henti Arah Keluar Indramayu di Ruas Jalan Pantura KM 46-47

Kecamatan Patrol Kabupaten Indramayu

\begin{tabular}{ccccccc}
\hline & \multicolumn{5}{c}{ Arah Keluar Indramayu } \\
\cline { 2 - 7 } Jenis & $\begin{array}{c}\text { Kecapatan } \\
\text { Kencana }\end{array}$ & Fm & $\begin{array}{c}\text { Jarak } \\
\text { Pandang Henti } \\
\text { Eksisting } \\
(\mathrm{m})\end{array}$ & $\begin{array}{c}\text { Kecapatan } \\
\text { Persentil 85 } \\
(\mathrm{km} / \mathrm{jam})\end{array}$ & Fm & $\begin{array}{c}\text { Jarak } \\
\text { Pandang Henti } \\
(\mathrm{m})\end{array}$ \\
\hline MC & 60 & 0,33 & $75-85$ & 62,78 & 0,325 & 91,4 \\
LV & 60 & 0,33 & $75-85$ & 78,26 & 0,302 & 134,2 \\
HV & 60 & 0,33 & $75-85$ & 56,25 & 0,337 & 76,1 \\
\hline
\end{tabular}

\section{Perlengkapan Jalan}

Kondisi perlengkapan jalan di sepanjang ruas yang diamati dievaluasi dengan melakukan survei inventarisasi ruas jalan. Hasil survei menunjukkan bahwa tidak terdapat rambu, kondisi marka yang telah memudar dan tidak sesuai ketentuan, serta penerangan jalan umum yang tidak berfungsi.

\section{Upaya Penanggulangan Masalah}

Sebagai upaya untuk mengurangi jumlah kecelakaan lalu lintas di ruas jalan yang diamati, pada studi ini diberikan beberapa usulan. Usulan tersebut didasarkan pada analisis faktor-faktor penyebab terjadinya kecelakaan lalu lintas.

\section{Manajemen Kecepatan}

Analisis yang telah dilakukan menunjukkan bahwa kecepatan tinggi menjadi faktor utama penyebab kecelakaan lalu lintas di ruas Jalan Pantura KM 46-47, Kecamatan Patrol, Kabupaten Indramayu. Selain itu juga diketahui bahwa semakin tinggi kecepatan, semakin panjang jarak yang dibutuhkan untuk berhenti.

Kecelakaan lalu lintas yang terjadi di ruas jalan yang diamati umumnya terkait dengan tingginya kecepatan lalu lintas di ruas jalan tersebut. Karena itu, perlu diterapkan manajemen kecepatan, untuk mengelola kecepatan lalu lintas, dalam rangka mewujudkan keseimbangan antara keselamatan dan efisiensi kecepatan kendaraan (Kementerian Perhubungan, 2015). Batas kecepatan pada ruas Jalan Pantura KM $46-47$ adalah 40 km/jam, sesuai dengan fungsi dan sistem jaringan jalan, yaitu arteri primer, penggunaan lahan dan tingkat kegiatan kawasan, serta geometrik jalan. Supaya penegakan batas kecepatan dapat terlaksana, diperlukan pengawasan oleh pihak Kepolisian Kabupaten Indramayu. Penegakan hukum terhadap pelanggar batas kecepatan perlu dilakukan agar masyarakat mengetahui akan adanya sanksi bila melanggar batas kecepatan. Selain itu, tindakan rekayasa diperlukan agar bila tidak ada pengawasan oleh pihak terkait, pengemudi kendaraan bermotor tetap 
waspada. Tindakan rekayasa, seperti pemasangan pita penggaduh, diharapkan dapat membuat pengemudi kendaraan bermotor merasa tidak nyaman saat melaju di atas batas kecepatan yang telah ditentukan.

\section{Kelengkapan Perlengkapan Jalan}

Melengkapi perlengkapan jalan yang diperlukan mencakup pengecatan ulang marka dan pemasangan rambu. Pengecatan ulang marka dimaksudkan agar marka dapat terlihat dan mampu mengarahkan arus lalu lintas dan membatasi daerah kepentingan lalu lintas. Marka pada ruas Jalan Pantura KM 46-47 yang memerlukan perbaikan adalah marka membujur garis putus-putus, marka membujur garis utuh, marka garis tepi luar dan marka garis tepi dalam, marka melintang garis utuh, dan zebra cross. Pemasangan rambu harus disesuaikan dengan jarak pandang henti, sehingga pengemudi tidak terlambat dalam mengambil keputusan atas bahaya yang ada di depannya. Rambu yang perlu ditambahkan di ruas jalan yang diamati adalah rambu peringatan hati-hati, rambu larangan menjalankan kendaraan dengan kecepatan lebih besar dari $40 \mathrm{~km} / \mathrm{jam}$, rambu peringatan akan banyak lalu lintas pejalan kaki, rambu petunjuk lokasi fasilitas penyeberangan pejalan kaki, dan rambu larangan memutar balik untuk kendaraan dari arah timur dan dari arah barat pada bukaan median di lokasi-lokasi tertentu.

\section{Perbaikan Penerangan Jalan}

Penerangan jalan pada ruas Jalan Pantura KM 46-47, Kecamatan Patrol, Kabupaten Indramayu, tidak berfungsi, sehingga membahayakan pengguna jalan yang melintasi ruas jalan tersebut. Karena itu, diperlukan perbaikan pada lampu penerangan jalan, sehingga dapat memberikan penerangan di malam hari atau saat keadaan cuaca membutuhkan penerangan.

\section{KESIMPULAN DAN SARAN}

Studi ini menunjukkan bahwa faktor utama penyebab kecelakaan yang terjadi di ruas Jalan Pantura KM 46-47, Kecamatan Patrol, Kabupaten Indramayu, adalah faktor manusia, khususnya yang berhubungan dengan kecepatan tinggi. Untuk memperbaiki kondisi yang ada, diusulkan penempatan perlengkapan jalan, khususnya rambu, yang disesuaikan dengan jarak pandang henti yang diperlukan oleh kendaraan bermotor yang melintasi jalan tersebut. Selain itu perlu juga diterapkan manajemen kecepatan sebagai bagian upaya meningkatkan keselamatan lalu lintas.

\section{DAFTAR PUSTAKA}

American Association of State Highway and Transportation Officials (AASHTO). 1993. AASHTO Guide for Design of Pavement Structures. Washington, DC. 
Aswardi, T, Saleh, S.M., dan Isya, M. 2017. Evaluasi Kecelakaan Lalu Lintas Ditinjau dari Aspek Jarak Pandang Geometrik Jalan dan Fasilitas Perlengkapan Jalan terhadap Simpang Sibreh. Jurnal Teknik Sipil, 1 Spesial Issue (1): 263-270.

Direktorat Jenderal Bina Marga. 1992. Standar Perencanaan Geometrik untuk Jalan Perkotaan. Departemen Pekerjaan Umum, Jakarta.

Kementerian Perhubungan. 2015. Peraturan Menteri Perhubungan Republik Indonesia Nomor PM 111 Tahun 2015, Tentang Tata Cara Penetapan Batas Kecepatan. Jakarta.

Pemerintah Republik Indonesia. 2009. Undang-Undang Nomor 22 Tahun 2009 tentang Lalu Lintas dan Angkutan Jalan. Jakarta.

Sukirman, S. 1999. Dasar-Dasar Perencanaan Geometrik Jalan. Bandung: Penerbit Nova. 